\title{
Feminist Standpoint Theory: Conceptualization and Utility
}

\author{
Lina Gurung
}

\begin{abstract}
Feminist Standpoint theory challenges the notion of conventional scientific practices that had excluded women from the inquiry and marginalize them in every aspect of knowledge benefits and construction. Amidst the prevalent controversies, standpoint theorists have proposed alternative knowledge construction with the theses of 'strong objectivity', 'situated knowledge', 'epistemic advantage', and 'power relations'. Feminist standpoint theory is claimed to be a successful methodology and the author support this argument based on the four reasons; the logic of discovery, insider-outsider position, study up, and methodological innovation. The author also put forwards the various challenges confronted by feminist standpoint theory and the justification given by the theorists. The cognitive, methodological, and epistemological interrogations toward this theory have widened its scope and adoption in social science research. The paper aims to suggest this analysis as the most suitable analytical and theoretical approach to do feminist inquiry which brings the understanding of feminist epistemologies as the most appropriate alternative approach of recent inquires against the dominant practices.
\end{abstract}

Keywords: feminist standpoint theory, feminist epistemologies, feminist methodology, feminist inquiry

\section{Introduction}

Along with the feminist movement in the 1970s, there was an equal concern with the conventional social sciences, which reflected the male values, knowledge, and experience. The academia was criticized for their scientific privileging of male biases that excluded and marginalized women (Henn, et al. 2013). It was largely questioned on the conventional forms of knowledge production and the power imbalances such conventional methodological practices would bring. Such practices had omitted women's experiences, downplayed their contribution, and over-generalized from men's practices (Henn, et al., 2013). Such researches and practice would discount the value of 'research subjects' and exploration that is necessary for understanding the fragmented and complex nature of women's lives. So feminists raised fundamental challenges concerning the purpose of social research.

Should feminist scholars account for an alternative knowledge production for women against the conventional notion of rationality in social scientific inquiry? How can research be created only for women to provide less partial and distorted analyses truly connected to women's lives? It provoked intense discussion in feminist researches about 'a distinctive feminist method of inquiry' connecting to epistemology, methodology, and methods and that place women's experience at the heart of their research. Feminist epistemologists turned skeptical to the limit of knowledge and account of dominant knowledge (Alcoff \& Potter, 1993). Feminist epistemological projects began to critique the conventional science in a monolithic way and evolved to reframe and reconceptualize its own perspective and the problems of knowledge adhering to various feminist epistemological approaches.

The embodied nature of research in conventional social research investigated, explained, and saw the society from the masculine perspective. Feminists have argued that the scientific discourses developed from such male perspective inherently silence those not included within the value of rationality and objectivity. Thus the women's subjectivity was devalued and women's lived experiences were reduced to a series of disconnected variables (Naples, 2007). Harding and Norberg (2005) have pointed out that the daily life activities of the dominant group do not provide them sufficient sources to develop such values and interest in their work. Feminist epistemologies demonstrate that the gender aspects in the research process is pertinent (Moloney, 1996). Feminists analyze woman's past to understand how patriarchal society has devalued them by formulating new understandings that transform the existing practices based on the contribution, values, and experiences of women in society (Huirem et al., 2020). Feminist researchers have claimed that their research projects have practical implications for improving women's lives (Harding \& Norberg, 2005). Feminist empiricism emerged largely as a critique of science from feminist scientists who have argued how the feminist values can improve the scientific methods adhering to the postpositivist assumptions (Doucet \& Mauthner, 2006). But they are not disconnected from the ideas of postpositivism completely. Feminist postmodernists such as Hekman too provided critiques of such postpositivist assumptions about science, rationality, and knowledge and emphasized the connections with gender relations (Moloney, 1996). In this background, the feminist standpoint epistemologies formed a major strand. They have challenged the differential power that groups have to define knowledge by arguing that the marginalized 
groups hold a particular claim to knowing (Doucet \& Mauthner, 2006).

Feminist standpoint theory has been the most controversial and debated in more than thirty years of history of second-wave feminist thinking (Harding, 2004). It is highly advocated as equal to its critics even today and has invited ongoing debate and reflection. It has continued to enflame discussion among feminist theorists. It looked into the inequalities between men and women in knowledge production from the epistemological perspective.

In general, standpoint is simply taken as an understanding or perspective of the world regarding its social position. However, Pilcher and Whelehan (2004) claim that the standpoint theorists have developed it into complex arguments about the production, status, and purpose of research-generated knowledge and has formed an important critique of traditional scientific epistemologies. In the feminist standpoint theory, the term "standpoint" is meant to designate a moral and political commitment and not merely a perspective on social reality (Rolin, 2009). So standpoint is not just a perspective occupied as a matter of fact of being a woman. Perspective may give a starting point of one's socio-historical position, but standpoint is earned through the experience of collective political struggle demanding both politics and science (Kokushkin, 2014). Thus it has now become a technical term that stresses the politics and science for achieving group consciousness through distinctive understandings of social relations in referring to dominant perspectives as well as to those of oppressed groups (Harding, 2004). So Feminist standpoint theory is engaged in complex conversation of knowledge production. In fact, it is a way for them to understand and explain the social world from the vantage point of women's lives (Schraner $\&$ Ho, 2004). For standpoint theorists, standpoint refers not to perspective or experience but to an understanding of perspective and experience as part of a larger social setting reflecting political consciousness (Lenz, 2004). So it is not escapable from the epistemological issues. The linking of epistemological concerns with political action lies at the heart of feminist standpoints (Hartsock, 1997).

This paper aims at giving a clear picture of the need and account of feminist standpoint theory while discussing its major notions and strategies for knowledge production. Further, this paper also put forward candidly the charges to these perspectives and their justifications. This is a literature-based theoretical paper and thus deal with the scope and challenges of adopting Feminist Standpoint Theory. Amidst the contentions, I aim to propose this theory and methodological inquiry as adaptable, resourceful, and widespread in social sciences.

\section{The Historical Root of Feminist Standpoint Theory}

A paper entitled 'The Feminist Standpoint: Developing the Ground for a Specifically Feminist Historical Materialism' (1987), by social scientist Nancy Hartsock was the most influential and initial work to put forward the conception of standpoint theory (Schraner \& Ho, 2004). However, American Feminist theorist Sandra Harding coined the term standpoint theory to categorize epistemologies that emphasize women's knowledge. Then standpoint theory or standpoint epistemology became recognized around the mid-1980s as a strand of feminist analysis through the work of the feminist philosopher of science, Sandra Harding - in her The Science Question in Feminism and throughout her subsequent work.

Feminist standpoint theory is a broad categorization that includes somewhat diverse theories ranging from Hartsock's (1983) Feminist Historical Materialism perspective, Donna Haraway's (2003) analysis of Situated Knowledge, Patricia Hill Collin's (1990) Black Feminist Thought, and Smith's (1987) Everyday World Sociology For Women (as cited in Naples \& Gurr, 2013).

The original feminist standpoint theory operated from a materialist base. It is conventionally traced from the master-slave relationship from Hegel's reflections and the Marxist classic theory (Harding, 1997) where the bourgeoisie is replaced with men and the proletariat with women. Nancy Hartsock sees Hegel's master-slave relationship as the foundation for gender relations where women are inherently oppressive as the master can ever only be a man (Changfoot, 2004).

Dorothy Smith has argued that the origin of the standpoint of women was not the Hegelian and Marxian insights but began in women's experiences yet unformulated and unformed even before its women's political movement (Smythe, 2009). According to Harding (1992), "this theory of knowledge refuses fully to address the limitations of the dominant conceptions of method and explanation and the ways the conceptions constrain and distort results of research and thought about this research even when they are most rigorously respected". Thus for Harding, it represents a successor science that aims to reconstruct the practice and purpose of science (Harding 1986, as cited in Pilcher \& Whelehan, 2004). Walby (2001) explained that standpoint theory helped in creating an intellectual space for feminist analysis which was previously seen antagonistic but later it was used in the women's movement related to consciousness-raising groups (as cited in Schraner \& Ho, 2004). It then continued to be a widespread practice of women's movements all over the world.

It is a feminist theoretical perspective that denies the objectivity of scientific research for ignoring and marginalizing women and feminist ways of thinking (Swigonski, 1994). In fact standpoint theory is a type of critical social theory aimed to empower the oppressed to improve their situation which was largely ignored in social-political theories and movements. It emerged from the critical theoretical approaches within a range of social science disciplines. Steckle (2018) argue that standpoint does not only produce alternative stances alongside the dominant ones, rather it creates spaces of critical tension of how uncritically the dominant forms of knowledge have been constructed and deployed. So the feminist standpoint epistemologies draw on women's lives as enabling and epistemologically privileged vantage point on the workings of male supremacy and its interaction with the social relationships of capitalism (Schraner \& Ho, 2004). 


\section{Principle Theses of Feminist Standpoint Theory (FST)}

Feminist standpoint theory has indeed made a major contribution to feminist theory and has developed more useful ways of thinking about the production of knowledge in local and global political economies (Harding, 1997). All the scholars of Feminist Standpoint Theory were from diverse disciplines and worked more or less independently of each other. They all maintained that marginalized groups of people occupy a unique position and are less partial than those who hold societal power. It accounts for the multiplicity of women's perspectives and the diversity of women's experiences (Hawkesworth, 1999). A tenet of feminist standpoint theory is that women's subordinate status in the sex-gender system leads to experiences that can produce a feminist consciousness about gender (Martin, et al., 2002). To be specific, standpoint theory is guided by the four main theses:

\section{Strong Objectivity}

Sandra Harding is counted as the most well-known feminist theorist of strong objectivity. For Harding, strong objectivity involves an analysis of the relationship between both the subject and object of inquiry (Naples \& Gurr, 2013). The objective knowledge sees its conceptual procedures, methods, and relevance to organize its subject matter from a determinate position in society. So according to Harding (1993), the notion of objectivity is transformed into 'strong objectivity' by the logic of standpoint epistemologies and it is useful in providing a way to think about the gap that should exist between how any individual or group wants the world to be and how it is. The strong objectivity requires what we can think of as 'strong reflexivity'.

Feminist scholars who approach the research process from the view of strong objectivity are also interested in revealing the relations of power that are hidden in conventional knowledge production processes. (Naples \& Gurr, 2013). So this objectivity acknowledges that the production of knowledge is highly related to power and it is a political process that has to be dealt with prominently. Maria Mies (2007) who claims that there is an intrinsic relationship between capitalism and patriarchy has postulated that the value-free research of 'objectivity', neutrality, and indifference of the researcher vis-à-vis the research objects has to be replaced by consciously taking sides for the oppressed. She urges for the collective conscientization of women, furthered by a problem formulating and solving research methodology by more researches on the study of women's individual and social history (Mies, 2007).

Another feminist, Ann Oakley particularly focused on the 'democratization of ways of knowing' arguing for a reflexive relationship between the researcher and the research (Oakley, 2000). Oakley argues that experimental research can produce more credible and democratic knowledge which has been undermined by the 'subjectobject' divide. So there are different standpoints on the feminist methods which are making the women's agency increasingly complex within the complex matrix of domination and subordination (Wallace, 2007). So more researches are necessary to be carried out and feminist standpoint theory as an alternative epistemology in social sciences research can fulfill this need. Feminist standpoint theory as put forward by Sandra Harding through 'strong objectivity' is an attempt to make the complex simpler and justifiable.

The strongest objectivity is found through the marginalized feminist perspective. According to her, these perspectives can guarantee the most accurate and least distorted view of the world. Usually, males hold powerful positions and thus try to preserve the status quo and are not interested in considering other's perspectives. It is the notion that perspectives of marginalized and oppressed individuals can help to create more objective accounts of the world. It emphasizes the importance of starting from the experiences of those who have been traditionally left out of the production of knowledge. It is also the strategy to start research from the lives of women and other marginalized groups to provide a less false view of reality. This epistemology can bring drastic changes in bringing women's voices in social science research and grooming women researchers. It acknowledges that the social location of knowledge producers and the social context of the knowledge production contribute to more transparent and ethical research claims (Naples \& Gurr, 2013). Therefore this strong objectivity in a research process can promote gender equality with the less distorted truth.

\section{The Situated-Knowledge}

Social location systematically influences our experiences, shapes, and limits what we know, thus knowledge is achieved from a particular standpoint (Wylie, 2003). The situated-knowledge thesis has been interpreted as the claim that women have a distinct way of knowing different from that of men (Intemann, 2010). Contemporary standpoint theorists, however, have denied that standpoints are merely socially located perspectives. Rather, standpoints are said to be achieved through a critical, conscious reflection on how power structures and resulting social locations influence knowledge production. For Harding, a standpoint is a distinctive insight into how hierarchical social structures work (Harding 2004). Standpoint theory claims that some kinds of social locations and political struggles advance the growth of knowledge, contrary to the conventional view that politics and local situatedness can only block scientific inquiry (Harding, 2004). Marginalized groups are socially situated in a way that makes it more possible for them to be aware of things and ask questions (Kokushkin, 2014). For example, the women from a Dalit community or indigenous group have unique experiences which demand the understanding of their situated knowledge by the researcher. Thus the standpoint claims that all knowledge attempts are socially situated and that some of these objective social locations are better than others as starting points for knowledge projects and challenges some of the most fundamental assumptions of the scientific world view (Harding, 1992). If we start of research framing from the viewpoint of a Dalit women on their social and economic development of a nation can challenge such fundamental assumptions from the beginning and it will guide the whole research with a widened horizon and comprehensive knowledge 
production. In this way, it values Dalit women's experiences, needs, and perceptions of the social world.

Knowledge claims are socially situated, and the failure by dominant groups critically and systematically to interrogate their advantaged social situation leaves their social situation a scientifically and epistemologically disadvantaged one for generating knowledge. And these accounts end up legitimating exploitative 'practical politics even when those who produce them have good intentions (Harding, 1993). Therefore the situated knowledge questions the conventional ways of valuing the knowledge and disrupts such legitimization of dominant groups. For instance, it criticizes the privileged status of western science which is tolerated at the expense of local and indigenous knowledge systems that are marginalized. This theory sees neutrality as a problematic principle as it does not challenge the production of systematically distorted results of research (Trosow, 2001). Mostly in natural science and some social sciences of positivistic paradigm, such neutrality is perceived essential for scientific inquiry. Therefore standpoint theory helps in proceeding in a fruitful direction by lowering the use of neutrality and provides scrutiny for creating systematic distortions of reality. So I argue that standpoint theory can help in identifying the deliberate discrimination of women's knowledge in conventional research and aims at bringing transformation through highlighting the manifold aspects of gender relations.

\section{Epistemic Advantage}

The thesis of epistemic advantage has been understood as claiming that women always have an automatic epistemic privilege in virtue of being oppressed (Intemann, 2010). Standpoint theory argues that the knowledge and theories of marginalized populations hold more epistemic authority than the knowledge and theories developed by dominant groups. As the oppressed groups have to endure many struggles and pain, they have complete or diverse knowledge on the account of their lower status. It is assumed within standpoint theory that dominant groups will be limited in their epistemic perspectives to their own values and perspectives, unable to gain a wider view of interests and experiences, but that marginalized groups can attain a more global perspective that not only begins in their own experiences but also includes consideration of the dominant ideologies to which they are subjugated. Thus members of marginalized groups have a kind of double vision that allows them to understand social contexts broadly because they are not only experiencing their own realities but also witness other realities through their engagement with dominant groups. This provides them with a better foundation for their worldviews and their standpoint. Members of dominant groups have a more restricted perspective, limited by their avoidance of 'downward mobility' and the invisibility of the work performed by those in other social classes (Naples \& Gurr, 2013).

Martin, et al., (2002) conducted a study with federal judges applying feminist standpoint theory. In the study, they have argued that women are more conscious of gender inequality because they occupy a devalued gender status and as a result have negative experiences. They have also argued that these experiences impel women, more than men, to develop a feminist consciousness and that these gender differences have implications for the legal institution. The study explores how a feminist consciousness is achieved, as standpoint theorists say it necessarily must be, by exploring the intersections of social location, observations/ experiences, and consciousness. Using feminist standpoint theory they asked if women and men legal professionals are similarly conscious of gender inequality and similarly observant of the gender-biased processes that produce it. Standpoint theory suggests that women's greater experiences of gender-based discrimination sensitize them to these issues. Women thus should be more attuned to gender bias in cases that come before them and in the social relations that constitute the practice of law (Martin, et al., 2002). In this way, feminist standpoint theory offers both a theoretical perspective and a method for studying gender in the legal institution.

Standpoint theorists argue that starting research from women's lives will generate less partial and distorted accounts not only of women's lives but also of men's lives and of the whole social order (Harding, 1993). For instance, to carry out research on the impact of any development activities, the women and men are impacted differently as their needs are also different so the researcher being conscious of this phenomena, can apply the feminist data collection and generation process that acknowledges this epistemic privilege and guarantee reliable research results.

\section{Power Relations}

Feminist standpoint theory urges feminists to reflect on relations of power as a distinctive kind of obstacle to the production of scientific knowledge. The obstacle is not adequately conceptualized as a cognitive bias that a social scientist may be vulnerable to; it is more adequately conceptualized as a social phenomenon that is endemic in the world of power relations (Rolin, 2009). Allen (1989) refers to power as the ability of an individual or a group to constrain the choices available to another individual or group (as cited in Trosow, 2001). Rolin (2009) states that there may not always be domination in power relations but they function as instruments of domination to harm other's choices and it mobilizes a complex set of motivations in distorting the relevant evidence.

Standpoint theory highlights the importance of relations of power in the production of knowledge. As a methodology, standpoint theory provides both a means of uncovering the power relations that create such silence and the trust necessary to access informants' evidence (Crasnow, 2009). Since a standpoint specifies a power relationship, one way to understand how power works is to learn from the standpoint of the less powerful. According to Harding (2004), we can use the accounts of the less powerful to gain insights into how power operates and to reveal differences between what is 'claimed' to be true and what people experience. For example, bring the stories of Dalit women who have faced domestic violence. Such narratives are powerful to get the picture of the society they live with and the suppression they face, which would not have been possible from the study's value-free 
objective. Rolin (2009) has summarized the insights of feminist standpoint theory as a methodology for the study of power relations. One insight is that relations of power can suppress or distort relevant evidence, and, therefore, they pose a special challenge for social scientists who aim to understand them. Another insight is that the process of generating evidence needs to be coupled with a process of empowerment if social scientists are to generate evidence under suppressive social conditions (Rolin, 2009). Ethics is highly important in any research process to maintain relationships with the research participants and ensure their safety and confidentiality. A feminist standpoint approach can reveal how the legal institution operates as a paradoxical mechanism that both reinforces and challenges sexism and racism, as the era of the Civil Rights and women's movement showed. (Martin et al, 2002).

Harding and Norberg (2005) have claimed that "in challenging conventional epistemologies and their methodologies, both of which justified problematic understandings of research methods, feminist have contributed to the epistemological crisis of the modern west, or north" (p. 2010). Thus, the feminist standpoint theories are the alternative methodologies best suited for the social sciences and highly relevant in the south and eastern regions to prioritize the excluded knowledge production system by rebalancing the power relations. Further, it makes the feminist research politically and ethically accountable to the disadvantaged groups and eliminate the power differences between the researcher and the researched (Harding and Norberg, 2005). Rolin (2009) has summarized the insights of feminist standpoint theory as a methodology for the study of power relations.

\section{Methodological Strategies for Inquiry in FST}

Feminist standpoint theory begins with its successes as a methodology, particularly in the social sciences. These strongly suggest that there is something worth exploring in standpoint theory, even if it is not possible to develop it fully as a feminist epistemology (Crasnow, 2009). The methodology of standpoint theory posits that no truth claims are devoid of political investment, its objective is in part to expose the political investment, objective is in part to expose the political investment surrounding otherwise unexamined and generally accepted 'truths' (Lenz, 2004). It criticizes conventional science and has developed itself as a methodological approach that takes the ground of inquiry from the lived experiences of marginalized groups especially women.

Feminist standpoint theory as a methodological tool can guide feminist inquiry by offering several advantages (Hawkesworth, 2006) in social science research in terms of its attention to the production of knowledge and methodological innovation. Four reasons explain the best application of feminist standpoints as an analytical tool to conduct any feminist research.

\section{Logic of Discovery}

Feminist standpoint research projects propose a 'logic of discovery' or the fundamental map of how to undertake the process of knowledge construction. Feminists who have fully articulated this standpoint epistemologies have claimed to provide such logic or fundamental map (Harding, 1992). They recommend starting from the lives of groups marginalized and exploited through policies issuing from and legitimated by the conceptual frameworks of, for example, primatology, education, technology, and development sciences. (Harding, 2004). Feminist standpoint theory is a resource for feminist epistemology and philosophy of science as it guides or outlines a method for producing scientific knowledge under social circumstances that, given all other conditions, undermine attempts to generate evidence (Rolin, 2009). It suggests a way of gathering information for analysis and presupposes multiplicity and complexity (Hawkesworth, 2006).

Dorothy Smith points out that if we start from women's lives, we can generate questions about why it is that it is primarily women who are assigned such activities, and what the consequences are for the economy, the state, the family, the educational system, and other social institutions of assigning body and emotional work to one group and head work to another (Harding 1992). This kind of question before the analysis guides the researcher to design their methods. Smith talks about the mode of inquiry which is about everyday world institutional ethnographic approach to epistemology. Smith (1992) explains that her approach does not privilege a subject of research whose expressions are disconnected from her social location and daily activities. Rather she starts inquiry with an active knower who is connected with other people in particular and identifiable ways. This mode of inquiry calls for explicit attention to the social relations embedded in women's everyday activities. Smith's (1992) analysis of standpoint as a mode of inquiry offers a valuable methodological strategy for exploring how power dynamics are organized and experienced in a community context (Naples \& Gurr, 2013).

Standpoint theorists themselves all explicitly argue that the claim by women that women's lives provide a better starting point for thought about gender systems is not the same as claiming that their own lives are the best such starting points (Harding, 1992). This does not mean that they deny their own epistemic advantage but different women's lives are resourceful.

\section{The position of an 'insider-outsider'}

Standpoint theorists have argued that members of oppressed groups sometimes have special experiences that result from their location as 'insider-outsiders' (Hill Collins, 1991 as cited in Intermann, 2010) or 'outsider within' (Lenz, 2004). Being a female researcher, she becomes an "insider" that enables her to understand and identify assumptions that are being made in her field. Yet, she is an outsider in the conventional researches where her values are historically excluded from such research. This experience allows her to identify the limitations and problems with some of those assumptions (Intermann, 2010). In the case of a male researcher, the position could be 'outsider-insider' where he is an outsider as a male and an insider as a researcher who starts with experiences of the lives of marginalized people. It focuses on the investigation of marginalized points of view (Lenz, 2004). This position of 'insider-outsider' is a unique position of 
a researcher. In particular, their experiences as "insideroutsiders" put them in a particularly strong position to reveal evidence that has been historically excluded from scientific communities (Intermann, 2010). So there is an epistemic advantage of the 'double vision' within the recurring theme of feminist standpoint theories. This double vision or dual perspective allows them to recognize the underlying assumptions that shape the dynamics of power within the scientific inquiry. As a result, they are more likely to identify limitations or problems with background assumptions that have gone systematically unnoticed (Intermann, 2010). This method focuses on outsider perspectives and elaborates the investigation of marginalized points of view (Lenz, 2004). Through the outsider-within phenomenon, these individuals are placed in a unique position to point to patterns of behavior that those immersed in the dominant group culture are unable to recognize. They challenge the status quo as the outsider within. The status quo representing the dominant group and male position of privilege.

There have been various opinions on the insider and outsider position of a researcher on the aligned issues. Many feminists point out the necessity to have a similar experience or be a member of the same group to do particular research. For instance, they prefer to have Dalit woman but no one else, to research on Dalit women given that the women researcher's position as an insider as well as an outsider. Likewise, Tamney et al, (1992) stated that men never understand the various frustration women go through since they do not encounter such discrimination of suffering (as cited in Huirem, 2020). Therefore, we need to understand that 'outsiderness' and 'insiderness' are not fixed or static positions as claimed by Naples (1996). So it is also about the relationships of a researcher's position or experience with the subject which is shifting in the changing society. Therefore the situated knowledge, balanced power relationships, social locations, and starting with the perspectives of excluded and oppressed individuals or groups are the pertinent features that make the research good research with accountability toward the subjects.

\section{Study Up}

Much of the early feminist research was understood to have 'studied up', focusing its explanations on dominant social institutions and their ideologies, rather than to have 'studied down' by trying to explain the lives of marginalized groups (Harding 2004). According to Harding, this is the important difference between 'perspectivalism' and 'standpoint theory'. This can be carried out by locating oneself in a politically disadvantaged or oppressed situation and bring distinctive insights about how a hierarchical social structure works (Harding, 2004). The 'study up' approach tends to be critical and explain how the social structure of society works excluding women in the scientific inquiry and not acknowledging their cognitive styles rather than explaining the beliefs and behavior of conventional social sciences have usually done (Harding 2004). Its focus lies on claims, inquiries, and frameworks that endorse hierarchies and breed marginalization. Here the relationship between the oppressor and the marginalized is entangled. The goal of standpoint projects is thus "study up". It doesn't emphasize conventional ethnographies but sets out to explain what oppressed groups need and want to know about why and how so much poverty and misery accumulate in their daily lives while riches and pleasures accumulate in the daily lives of dominant groups (Harding, 2009). It is overtly political. Instead of studying the powerful that govern, by studying up, researchers can identify the conceptual practices of power and how they shape daily social relations (Harding \& Norberg, 2005). Therefore the studying up methods is a part of critical studies which is a crucial process in understanding the power relations and how it influences the practices in the society. To understand the perspective of the marginalized group or about the excluded and oppressed situations they experience, this inductive method can best address such issues.

\section{Methodological Innovation}

Feminist standpoint theory advises a social scientist to couple the process of generating evidence with a process of empowerment (Rolin 2009). And when it is about empowerment, transformative praxis, liberating women from discrimination, it makes the research accountable for whatever is done in the process of research. This allows the researcher to bring more ingenuity and generate artistic power to start off and knowledge generation. So this methodology is conceived as a "creative stance" or enhance creative ability. According to Crasnow (2009), theories of creativity help us to understand what works in standpoint theory, and standpoint theory help to understand creativity more generally. Hawkesworth (2006) argues that feminist standpoint theory deployed as an analytical tool affords an innovative means for the identification and interrogation of competing for theoretical presuppositions. Harding (2009) supports by saying that it provides a logic of research that focuses on problems that are deeply disturbing to anyone reflecting on contemporary challenges to western thought and practice and yet insoluble within the philosophical, political, and theoretical legacies that they provide. One of the most prominent tenets of feminist standpoint theory is 'multiple subjectivities' or 'plurality' and for this, it uses comparative and competing views as a strategy for knowledge production (Hawkesworth, 2006). Standpoint analysis imposes a responsibility on the researcher which engages them in a comprehensive way for examining the in-depth and alternative fair views.

Dorothy Smith talks about the standpoint of men who are located within the 'relations of the ruling' our societies in her article 'What It Might Mean to Do a Canadian Sociology: The Everyday World as Problematic'. She writes 'the concept of a problematic is used in part to bring the sociologist and the sociological inquiry into a different relation to the society by constituting the everyday world as that in which questions originate' (Smith, 1987). While reviewing her article, A concern with putting epistemology into practice makes her very unusual amongst current feminist theorists. According to Gallaghar (2000), Smith has problematized the very sociology we have used to study human relations and pointed to new feminist research strategies in the field. She states, 
Smith's (1987) feminist methodology is interested in realizing sociology for women that is more than an acknowledgment of a particular standpoint or perspective. It does not universalize a particular experience. It is rather, "a method that from the outset of the inquiry, creates a space for an absent subject, and absent experience to be filled with the presence and spoken experience of actual women speaking of and in the actualities of their everyday worlds (p. 107)"

Gallaghar (2000) has applied this same concept of Dorothy that the everyday world as problematic in a classroom setting. She has explored the distinct experiences of girls within the traditional classroom operated by patriarchal structures and practices. She emphasized the feminist pedagogy to expose the social relations that construct our classroom realities and address the girls' experience in necessary ways. Similarly, this concept and method of looking into the everyday world of women as problematic especially in the digital world where women experience digital marginalization compared with men can be best relevant. It can bring the experiences of women about how their limited knowledge in the digital age pushes them to the state of marginalization, less confidence, uninformed and inferior feelings. According to Swigonski (1994), adaptation to this approach to research could bridge the gap between research and practice, permitting true practitioners or researchers and leading to social change. However, as a methodology, it has been disseminated across many research disciplines and is today often used to frame research projects (Harding, 2004). This methodology in feminist research is more referred to in social sciences. Various versions of standpoint theory have been applied in a range of empirical studies across many disciplines. Any research projects on knowledge production can find active ways to incorporate into their principles of 'good method' to use history as a resource by socially situating knowledge projects in the scientifically and epistemologically most favorable historical locations (Harding, 1993). Overwhelmingly it offers the methodological creativeness for not claiming the distorted truths in any discipline or areas of researches.

\section{Paradoxes Within and Responding to Myths}

There is hardly any such theory that has remained as controversial as feminist standpoint theory for more than four decades. Feminist Standpoint epistemology challenged the dominant pre-feminist epistemology and philosophy of science where everyone had wondered about the insights feminists wanted to offer (Harding, 1992). There have been many questions raised to the theoretical position of the standpoint theorists such as; what is the process through which a standpoint is achieved, and how can that standpoint be recognized? Is a stable, categorically clear identify a prerequisite for a standpoint? Is it possible to have multiple, changing standpoints and if so how can the insights and analyses provided by those standpoints be communicated? Does the outsider within really have a privileged standpoint (Lenz, 2004)? These kinds of questions have been raised frequently for which the standpoint theorists have clarified the cost of revisiting their pre-assumptions. Although this critique continues, constructive and reconstructive work in the theory of knowledge is still emerging today (Alcoff \& Potter, 1993)

Harding, a prominent theorist herself identifies the various controversies and finds it as a resource understanding standpoint theory as a logic of inquiry. Critics are concerned more about the divergence in standpoints raised by feminists concerning political and epistemological issues, given their convergence in standpoint projects (Crasnow, 2009). So it covers the most significant epistemological dilemmas of the era. (Harding, 2004). Standpoint theorists believe that long time persistence to the controversies proves the strengths, power, and social relevance of the theory.

Susan Hekman reasons in her consideration of standpoint theory, "If there are multiple feminist standpoints, then there must be multiple truths and multiple realities and this is a difficult position for those who want to change the world according to a new image" (Hekman 2000, p.19). This difficulty is addressed by Patricia Hill Collins, who insists in her response to Hekman that "the notion of a standpoint refers to historically shared, groupbased experiences which transcend individual experiences and standpoint theory places less emphasis on individual experiences within socially constructed groups than on the social conditions that construct such groups" (Hekman, 2000, p. 43)). Again, the individual experiences and their interpretations vary among the members of a different social group. Standpoint theory recognizes that such variations deepen and strengthen our understanding of the positions at which various forms of oppression intersect (Lenz, 2004). Sandra Harding (1991) argues that science is improved when 'multiple subjectivities' about a social phenomenon are taken into account because multiple subjectivities produce a more complex and accurate 'objectivity' (Martin et al,, 2002).

The most controversial was the idea of not advocating epistemological relativism and rejecting universalism at the same time. The standpoint theorists in this regard argue that "some social situations are scientifically better than others to start off knowledge projects" (Harding, 1993, p.61). Also, they do not have a problem with non-neutrality which in a sense accepts relativism. In order to unveil the real, the researcher must be able to go underneath the surfaces of the problem to bring out new dimensions in the field of social sciences which no other feminist approaches can achieve (Huirem, et al, 2020). In Harding's view, the resulting plurality is itself a resource of feminist epistemology rather than a liability and suggests that we might be better off talking about standpoint theories than one standpoint theory (Crasnow, 2009). Achieving a standpoint is not about getting the ideal perspective but it is opposing the political limitations on perspectives (McClish \& Bacon, 2002).

There are various streams of feminism which start their analyses from different historical background. Liberal feminism initially started its analyses from the lives of educated class women in the eighteenth and nineteenthcentury in Europe and the US while Marxist feminism started from the lives of wage-working women of industrializing societies. Similarly, Third World feminism 
initiated with the third world lives. Here, Standpoint Theory argues that "each of these groups of women lives is a good place to start in order to explain certain aspects of the social order so the theory does not recommend any single or ideal woman's life to start with" (Harding, 1993. p.130). Thus different standpoint theorists have different ways to mark the beginning of this epistemology. Versions of standpoint theory have been applied in a range of empirical studies across many disciplines. Thus the agents of feminist standpoint theory are multiple within women's lives.

Postmodern feminist standpoint theorists argue that it is not possible to adjudicate between different versions of 'truth' but that exists are a multiplicity of unstable, diverse, and locally negotiated versions of the truth (Hekman, 1997). Here, Harding (1993, p.60) suggests that

one must turn to all the lives that are marginalized in different ways by the operative systems of social stratification". According to her (1993), "the different feminisms inform each other to learn and change the patterns of belief in the theory" (p.60).

So the writings of standpoint theorists have been reformulated. Hartsock concludes that whatever its shortcomings, standpoint theory has successfully produced 'a fertile terrain for feminist debates about power, politics, and epistemology (1998, p.230). This debate has contributed to the wider concerns in gender studies and feminist research theorizing the identity and knowledge construction of men and women. Kokushkin (2014) states that scholars outside of the feminist tradition can well use the feature of standpoint i.e decentering the production of knowledge to challenge existing paradigms and claim a position of marginalized that counters a dominant position of privilege. It is useful for such scholars to reclaim knowledge based on his/her groups' or individual experiences. The perspectives of women in different social locations can be better understood with the help of feminist standpoint theory because it places the lived experiences of the marginalized groups in the center of the research (Huirem, et al, 2020).

\section{Conclusion}

Feminist Standpoint Theory is a landmark in the feminist inquiry. It is most debated and advocated as it counters the pre-feminist and reductionist mainstream of philosophy of science by critiquing the traditional models of scientific inquiry and knowledge. The dominant knowledge practices excluded women from inquiry, denied their epistemic authority, denigrated feminine cognitive styles, trivialized their knowledge and contribution, reinforcing the gender hierarchies, and producing theories to serve the male interest. Thus the questioning of these practices was an utmost need which was contented by Feminist Standpoint Theory. So this theory is not merely a perspective that is ascribed simply of a being a woman. Instead, it is a political achievement of those whose social location forms its starting point. It is essential as a catalyst to open up one's eye to accept the multiple subjectivities. This attribute invites for a multiplicity of interpretations that can expand the meaning of any given or approached text. It also helps the non-feminists to redefine their exclusion and see the agency in themselves against the androcentric knowledge. Feminist standpoint theorist has revised and reformed their theory linking to its ever-expanding uses in actual research projects. Standpoint theorists have claimed this theory as an alternative to positivism and offer the ideas of multiple knower-positions, culturally and discursively grounded inexperience. This aspect of feminist standpoint theory generates it as a widespread analytical tool by accepting plurality as an inherent characteristic of the human condition and especially to the collective identity and yet multiple standpoints of women. Thus it deals with the dynamics of the individual, group, and communal identity.

Feminist standpoint theory urges a novel call for scientific analysis that complements the claims of it. The methodological resourcefulness is the strength of this claim. This theory also highlights the importance of power relationships in the process of knowledge production that aims at liberating women virtually from all forms of discrimination. It counters the analysis that limits the transformative potential of women's insights. Hence, it is also disciplinary to the extent that it seeks to transform the disciplines from within. As Gran said, it is a selfconsciously derived theoretical tool in the service of politics. Standpoint theory allows various strategies in knowledge construction which gives a sense of being engaged for the researcher as well as the participants. From its inception till its reconceptualization, it carries contention which is pertinent to value the perspectives in the society and revive the human relations with multiple standpoints. Importantly the relationship between knowledge and politics helps in claiming better truth in knowledge production. Surviving through the contentions, this theory and methodology have been worthwhile adopting with new insights, perspectives, and subjectivities pushing the limits of the researchers. This theory serves methods that make the researcher accountable and committed towards their subjects. Though this alternative approach to the conventional methodology has been widely criticized, it still accepts the contextual methodological innovation and inspires many women researchers to follow this new approach. This feminist epistemology theory is also necessary to build up a stronger alternative approach against the dominant androcentric practices It values the feminist epistemologies in the scientific research community. It contributes to mitigating the gender inequalities from the knowledge production system. Therefore I emphasize the more use of this method in the research to acknowledge the women's experiences and knowledge in knowledge construction.

\section{Ethics approval and consent to participate:} Not applicable

\section{Consent for Publication:}

Not applicable

Availability of data and materials:

Availability of data and material 


\section{Competing interests:}

The authors declare that they have no competing interests"

\section{Funding:}

No funding

Ethical conduct of the research:

Authors declare that this study has followed ethical conduct of research

\section{Authors' Contribution:}

The author has written the article solely.

\section{References}

Alcoff, L., \& Potter, E. (Eds.). (1993). Feminist epistemologies. Routledge.

Changfoot, N. (2004). Feminist standpoint theory, Hegel and the dialectical self: Shifting the foundations. Philosophy \& Social Criticism, 30(4), 477-502. https://doi.org/10.1177/0191453704044024

Crasnow, S. (2009). Is standpoint theory a resource for feminist epistemology? An Introduction. Hypatia, 24(4), 189-192. https://doi.org/10.1111/j.15272001.2009.01066.x

Doucet, A., \& Mauthner, N. S. (2006). Feminist methodologies and epistemology. In C. D. Bryant \& D. L. Peck (Ed.), Handbook of $21^{\text {st }}$ century sociology (pp. 26-32). Sage.

Gallaghar, K. (2000). The everyday classroom as problematic: A feminist pedagogy. Curriculum Inquiry, 30(1), 71-81. https://www.jstor.org/stable/3202130

Harding, S., \& Norberg, K. (2005). New feministapproaches to social science methodologies: An introduction. Signs: Journal of Women in Culture and Society , 30(4), 2009-2015. https://doi.org/10.1086/428420

Harding, S. (1992). Rethinking standpoint epistemology: What's "strong objectivity"? The Centennial Review, 36(3), 437-470. https://www.jstor.org/stable/23739232

Harding, S. (1993). Rethinking standpoint epistemology: What is 'strong objectivity'? In L. Alcoff \& E. Potter (Eds.), Feminist epistemologies (pp. 19-82). Routledge.

Harding, S. (1997). Comment on Hekman's 'Truth and method: Feminist standpoint theory revisited": Whose standpoint needs the regimes of truth and reality? Signs: Journal of Women in Culture and Society, 22(2), 382-391.

Harding, S. (2004). A socially relevant philosophy of science? Resources from standpoint theory's controversality. Feminist Science Studies, 19(1), 25-47. https://doi.org/10.1111/j.1527-2001.2004.tb01267.x

Harding, S. (2009). Standpoint theories: Productively controversial. Hypatia, 24(4), 192-200. https:/www. jstor.org/stable/20618189

Hartsock, N. (1998). The feminist standpoint revisited and other essays. Westview Press.

Hartsock, N.C.M. (1997). Feminist standpoint theory revisited: Truth or justice? Signs: Journal of Women in Culture and Society, 22(2), 367-374. https://www. journals.uchicago.edu/doi/10.1086/495159

Hawkesworth, M. (1999). Analyzing backlash: Feminist standpoint theory as analytical tool. Women's Studies
International Forum, 22(2), 135-155.

Hawkesworth, M. (2006). Feminist inquiry: From political conviction to methodological innovation. Rutgers University Press.

Hekman, S. (1997). Reply to Hartsock, Collins, Harding, and Smith. Signs: Journal of Women in Culture and Society, 22(2), 399-402. https://www.jstor.org/ stable/3175281

Hekman, S. (2000). Truth and method: Feminist standpoint theory revisited. In C. Allen \& J. A. Howard (Eds.), Provoking feminisms (pp. 9-34). The University of Chicago Press.

Henn, M., Weinstein, M., \& Foard, N. (2013). A critical introduction to social research (2nd ed.). Sage.

Huirem, R., Lognathan, K., \& Patowari, P. (2020). Feminist standpoint theory and its importance in feminist research. Journal of Social Work Education and Practice, 5(2), 46-55.

Intemann, K. (2010). 25 years of feminist empiricism and standpoint theory: Where are we now? Hypatia, 25(4), 778-796. https://doi.org/10.1111/j.15272001.2010.01138.x

Kokushkin, M. (2014). Standpoint theory is dead, long live standpoint theory! Why standpoint thinking should be embraced by scholars who do not identify as feminists? Journal of Arts and Humanities, 3(7), 8-20. https:// doi.org/10.18533/JOURNAL.V3I7.520

Lenz, B. (2004). Postcolonial fiction and the outsider within: Toward a literary practice of feminist standpoint theory. The National Women's Studies Association Journal (NWSA Journal), 16(2), 98-120. https://www. jstor.org/stable/4317054

Martin, P. Y., Reynolds, J. R., \& Keith, S. (2002). Gender bias and feminist consciousness among judges and attorneys: A standpoint theory analysis. Signs: Journal of Women in Culture and Society, 27(31), 665-701. https://www.journals.uchicago.edu/doi/ abs/10.1086/337941

McClish, G., \& Bacon, J. (2002). "Telling the story her own way": The role of feminist standpoint theory in rhetorical studies. Rhetoric Society Quarterly, 32(2), 27-55. https://doi.org/10.1080/02773940209391227

Mies, M. (2007). A global feminist perspective on research. In S. N. Hesse-Biber (Ed), Handbook of feminist research: Theory and praxis (pp. 663-668). Sage.

Moloney, M. (1996). Feminist social research: Epistemological and methodological implications [Honors thesis, Oberlin College]. https:// digitalcommons.oberlin.edu/honors/540

Naples, N. A. (1996). A feminist revisiting of the insider/ outsider debate: The "outsider phenomenon" in rural Iowa. Qualitative Sociology, 19(1), 83-106. https:// link.springer.com/article/10.1007\%2FBF02393249

Naples, N. A. (2007). Standpoint epistemology and beyond. In S. N. Hesse-Biber (Ed.), Handbook of feminist research: Theory and praxis (pp. 579-590). Sage.

Naples, N. A., \& Gurr, B. (2013). Feminist empiricism and standpoint theory: Approaches to understanding the social world. In S. N. Hesse-Biber (Ed.), Feminist research practice-A primer (2nd ed., pp. 14-41). Sage. 
Oakley, A. (2000). Experiments in knowing: Gender and method in the social sciences. Polity Press.

Pilcher, J., \& Whelehan, I. (2004). 50 key concepts in gender studies. Sage.

Rolin, K. (2009). Standpoint theory as a methodology for the study of power relations. Hypatia, 24(4), 218-226. https://www.jstor.org/stable/20618192

Schraner, I., \& Ho, C. (2004). Feminists standpoints, knowledge and truth (Working paper series). School of Economics and Finance, University of Western Sydney.

Smith, D. E. (1987). The everyday world as problematic: A feminist sociology. Northeastern University Press.

Smith, D. E. (1992). Sociology from women's experience: A reaffirmation. Sociological Theory, 10(1), 88-99. https://doi.org/10.2307/202020

Smythe, D. (2009). A few laced genes: Women's standpoint in the feminist ancestry of Dorothy E. Smith. History of the Human Sciences, 22(2), 22-57. https://doi. org/10.1177/0952695108101285

Steckle, M. (2018). Situating feminist standpoint theory: Toward a critical ontology of knowledge. [Unpublished master's thesis]. University of Windsor

Swigonski, M. E. (1994). The logic of feminist standpoint theory for social work research. Social Work, 39(4), 387-393. https://doi.org/10.1093/sw/39.4.387

Trosow, S. E. (2001). Standpoint epistemology as an alternative methodology for library and information science. The Library Quarterly: Information Communication, Policy, 71(3), 360-382. https://www. journals.uchicago.edu/doi/pdf/10.1086/603285

Wallace, S. (2007). Book review. Spontaneous Generations, 1(1), 151-157.

Wylie, A. (2003). Why standpoint matters. In R. Figueroa \& S. Harding (Eds.), Science and other cultures: Issues in philosophies of science and technology (pp. 2648). Routledge. https://onlinelibrary.wiley.com/doi/ abs/10.1111/j.1527-2001.2010.01138.x

Lina Gurung (https://orcid.org/0000-0003-4268-2575) is a Ph.D. Scholar at Kathmandu University, School of Education (KUSOED). She worked in KUSOED as a faculty from 2012 to2015. Currently, she is working as a gender coordinator in NORHED Project under KUSOED. Gurung is engaged in the education sector as a teacher in the school and higher education for almost two decades. Her research interest focuses on online and distance education, gender and technology, women and media, feminist pedagogy, gender and development, and genderresponsive curriculum.

Email: lina@kuseod.edu.np 